\title{
Intermittent fasting: a dietary intervention for prevention of diabetes and cardiovascular disease?
}

\author{
James E. Brown ${ }^{1}$, Michael Mosley ${ }^{1}$ and Sarah Aldred ${ }^{2}$ \\ 1. Aston Research Centre for Healthy Ageing \& School of Life and Health Sciences, Aston University, \\ Birmingham, B4 7ET, UK \\ 2. School of Sport and Exercise Sciences, College of Life and Environmental Sciences, University of \\ Birmingham. B15 2TT.
}

Address for correspondence: Dr James E Brown, Aston Research Centre for Healthy Ageing \& School of Life and Health Sciences, Aston University, Birmingham, B4 7ET, UK

Email: j.e.p.brown@aston.ac.uk

Telephone: 01212045039

Fax: 01212043696

\section{Abbreviations and Acronyms}

IFG - Impaired fasting glucose

IGT - Impaired glucose tolerance

IL-6 - Interleukin-6

\author{
LDL-C - Low density lipoprotein cholesterol \\ TAG - Triacylglyceride \\ TDEE - Total daily energy expenditure \\ TNF- $\alpha$ - Tumour necrosis factor alpha
}

\begin{abstract}
Intermittent fasting, in which individuals fast on consecutive or alternate days, has been reported to facilitate weight loss and improve cardiovascular risk. This review evaluates the various approaches to intermittent fasting examines the advantages and limitations for use of this approach in the treatment of obesity and type 2 diabetes.
\end{abstract}

Key words diet, fasting, intermittent fasting, obesity, type 2 diabetes, weight loss

\section{Introduction}

The increasing prevalence of obesity and type 2 diabetes in recent decades has been associated with increased comorbidities including atherosclerotic macrovascular disease and premature mortality (13). Individuals with sub-diabetic degrees of hyperglycaemia, such as IGT and IFG are also at increased risk of premature cardiovascular disease, emphasising the importance of interventions to improve glucose homeostasis in pre-diabetic, as well as diabetic individuals (4 -5). 
Several large studies have identified pre-diabetic individuals as subjects in whom to investigate lifestyle changes to prevent the progression to a fulminant diabetic state (6-10). However, there is considerable debate regarding the most effective manner in which lifestyle changes such as diet and/or exercise should be implemented (11). The approach of intermittent fasting is currently generating particular interest.

\section{Intermittent Fasting}

Extensive evidence suggests that imposing fasting periods upon experimental laboratory animals increases longevity, improves health and reduces disease, including such diverse morbidities as cancer $(12,13)$, neurological disorders $(14-17)$ and disorders of circadian rhythm $(18,19)$. The specific benefit of intermittent fasting as a health giving therapeutic approach has been recognised since the 1940's (20).

Intermittent fasting can be undertaken in several ways but the basic format alternates days of 'normal' calorie consumption with days when calorie consumption is severely restricted. This can either be done on an alternating day basis, or more recently a 5:2 strategy has been developed (Figure 1), where 2 days each week are classed as 'fasting days' (with $<600$ calories consumed for men, $<500$ for women). Importantly, this type of intermittent fasting has been shown to be similarly effective or more effective than continuous modest calorie restriction with regard to weight loss, improved insulin sensitivity and other health biomarkers $(1,21)$.

Fasting has been used in religion for centuries. For example, the Daniel fast is a biblical partial fast that is typically undertaken for 3 weeks, and during Ramadan, the ninth month of the Muslim calendar, there is a month of fasting during daylight hours, during which some observers also refrain from fluid consumption (22). Such periods of fasting can limit inflammation (23), improve circulating glucose and lipid levels (24-27) and reduce blood pressure (28), even when total calorie intake per day does not change, or is only slightly reduced. Ethical and logistical constraints have restricted most caloric deprivation studies to 6 months, although some have assessed the effects for longer (29-31). The majority of studies show positive effects on markers of metabolic health and body composition, in part due to the demonstrated effects intermittent fasting has on metabolic tissues (Figure 2). In addition caloric restriction studies undertaken in animals and humans have suggested that fuel selection is altered and efficiency of metabolism is improved $(32,33)$ while oxidative stress is reduced (34). It is possible that short periods of fasting mobilise ectopic TAG in non-adipose depots, reducing the detrimental effects of intra-myocellular and intra-hepatic TAG deposition (19, 35) and redistributing TAG into adipose tissue.

\section{Intermittent Fasting and Obesity}

Obesity comprises multiple genetic, metabolic and behavioural abnormalities that complicate treatment. Most pharmaceutical therapies that promote weight loss have been discontinued, and at the time of writing the only licensed anti-obesity drug on the UK market is orlistat (1). Increasing numbers of obese individuals are undergoing bariatric surgery, but this remains a restricted minority 
treatment (36). The mainstay of treatment for obesity therefore remains lifestyle intervention based around dietary changes (37-40) which generally form the first step in any weight loss programme.

Intermittent fasting is known to be useful in the treatment of intractable obesity (41), and morbidly obese individuals (42). Original treatment regimens were based upon intermittent starving as opposed to restricting calories $(43,44)$ a harsh regime that must have challenged adherence. Despite the seemingly strict nature of the fasting days intermittent fasting has a generally good adherence record and can cause significant reductions in body weight in individuals with obesity (45-46), suggesting that this is a clinically relevant therapeutic approach.

\section{Intermittent Fasting and Type 2 Diabetes}

Since obesity commonly coexists with type 2 diabetes (1) patients are usually initially assigned lifestyle interventions aimed at reducing body weight (46). Most obese type 2 diabetes patients however will progress onto drug based therapies, some of which can exacerbate their existing obesity (1). Intermittent fasting can reduce the incidence of diabetes in experimental animals (4749) and there is evidence that this type of fasting may also slow the progression of type 2 diabetes in obese individuals.

Indeed, a recent study confirmed earlier reports of a reversal of type 2 diabetes through daily calorie restriction, with improvement of pancreatic function and a reduction of occult triglyceride deposition (50). The particular diet employed a maximum of 600 calories every day, which may prove too severe for many type 2 diabetes patients, but an intermittent fasting strategy may be more acceptable and still improve metabolic parameters, insulin levels and insulin sensitivity $(51,52)$ and prevent the development of diabetic complications (53). Indeed, intermittent fasting might achieve much of the benefit seen with bariatric surgery (65), but without the costs, restriction on numbers and risks associated with surgery.

Whether intermittent fasting can be used as a tool to prevent diabetes in those with IGT or IFG, or to prevent progression in those recently diagnosed with type 2 diabetes remains a tantalising notion.

\section{Intermittent Fasting and Cardiovascular Disease}

Although with up to $80 \%$ of obese type 2 diabetes patients die from cardiovascular complications $(54,55)$ and the benefits of weight loss well recognised $(56)$ it is also known to be more difficult for individuals with type 2 diabetes to lose weight $(57,58)$.

Intermittent represents a potential therapy for those at high cardiovascular risk. Intermittent fasting in animal models can reproduce some of the cardiovascular benefits such as improvements in blood pressure and heart rate that are seen with physical exercise (59). Caloric restriction studies have shown improvements in circulating cholesterol, triglycerides, improved blood pressure, and reduced carotid intima-media thickness $(28,60)$. Also, improvements in physiological cardiovascular parameters are associated with intermittent fasting and survival from I myocardial ischaemia (61) through pro-angiogenic, anti-apoptotic and anti-remodelling effects. 
Intermittent fasting also appears to be cardioprotective, providing experimental animals with resistance to ischaemic injury (62), in a manner possibly associated with increases in levels of the adipokine adiponectin (63). Adiponectin is a unique adipokine that appears to have beneficial effects but has circulating levels that are negatively correlated with body composition $(64,65)$. However, intermittent fasting modulates the levels of visceral fat and several additional adipokines, including leptin, IL-6, TNF- $\alpha$ and IGF-1 (66). These changes are responsible for a reduction in LDL-C and total cholesterol, consistent with a potentially beneficial effect on cardiovascular risk. Although most fasting is generally regarded to reduce cardiovascular risk, over-zealous fasting for protracted periods is not without risks of reducing myocardial mass alongside reductions in other components of reduced lean body mass.

\section{Conclusion}

The use of intermittent fasting offers the potential to improve weight loss and enhance the cardiovascular health of overweight and obese individuals with type 2 diabetes and reduces cardiovascular risk. This type of intervention is cost-effective and associated with a low risk of adverse events.

\section{Key messages}

- Intermittent fasting promotes weight loss in obese individuals

- Limiting calories in this way can reverse diabetes

- Intermittent fasting is potentially cardioprotective

\section{Figure Legends}

Figure 1. Diagrammatic representation of a typical intermittent fasting plan. Subjects who undertake this form of diet are required to limit their calorie intake for two days, consecutively or otherwise each week. The calorie limit for fasting days is approximately $25 \%$ of TDEE or 600 calories for men and 500 for women. On nonfasting days subjects can eat normally to their TDEE calorie level (approximately 2500 for men and 2000 for women).

Figure 2. Tissue-specific effects of intermittent fasting and calorie restriction. Research has identified several biological effects of intermittent fasting and/or calorie restriction on tissues that are central to metabolic and cardiovascular health. Key: $\mathrm{NO}=$ nitric oxide, $\mathrm{TAG}=$ triacylglycerides. 


\section{References}

1. Kyrou I, Kumar S. Weight management in overweight and obese patients with type 2 diabetes mellitus. Br J Diabetes Vasc Dis. 2010;10:274-83.

2. $\quad$ Day C. The rising tide of type 2 diabetes. Br J Diabetes Vascr Dis. 2001;1:37-43.

3. Day C. Metabolic syndrome, or What you will: definitions and epidemiology. Diabetes Vasc Dis Res. 2007;4:32-8.

4. Petersen JL, McGuire DK. Impaired glucose tolerance and impaired fasting glucose - a review of diagnosis, clinical implications and management. Diabetes Vasc Dis Res. 2005;2:9-15.

5. Unwin N, Shaw J, Zimmet $P$ et al. Impaired glucose tolerance and impaired fasting glycaemia: the current status on definition and intervention. Diabetic Med. 2002;19:708-23.

6. Kosaka K, Noda M, Kuzuya T. Prevention of type 2 diabetes by lifestyle intervention: a Japanese trial in IGT males. Diabetes Res Clin Prac. 2005;67:152-62.

7. Pan XR, Li GW, Hu YH, et al. Effects of diet and exercise in preventing NIDDM in people with impaired glucose tolerance. The Da Qing IGT and Diabetes Study. Diabetes Care. 1997;20:537-44. 8. Sartor G, Schersten B, Carlstrom S et al. Ten-year follow-up of subjects with impaired glucose tolerance: prevention of diabetes by tolbutamide and diet regulation. Diabetes. 1980;29:41-9. 9. Tuomilehto J, Lindstrom J, Eriksson JG et al. Prevention of type 2 diabetes mellitus by changes in lifestyle among subjects with impaired glucose tolerance. New Engl J Med. 2001;344:1343-50.

10. Perreault L, Pan Q, Mather KJ et al. Effect of regression from prediabetes to normal glucose regulation on long-term reduction in diabetes risk: results from the Diabetes Prevention Program Outcomes Study. Lancet 2012;379:2243-51.

11. EH Schwarz P. Preventing type 2 diabetes - how to proceed? Br J Diabetes Vasc Dis. 2011;11:158-60.

12. Thomas JA, 2nd, Antonelli JA, Lloyd JC et al. Effect of intermittent fasting on prostate cancer tumor growth in a mouse model. Prostate Cancer and Prostatic Dis. 2010;13:350-5.

13. Buschemeyer WC 3rd, Klink JC, Mavropoulos JC et al. Effect of intermittent fasting with or without caloric restriction on prostate cancer growth and survival in SCID mice. The Prostate. 2010;70:1037-43. 9.

14. Hartman AL, Rubenstein JE, Kossoff EH. Intermittent fasting: A "new" historical strategy for controlling seizures? Epilepsy Research. 2012. doi:10.1016/j.eplepsyres.2012.10.011 (The publication hasn't been printed hard copy yet so just has a doi)

15. Singh $\mathrm{R}$, Lakhanpal $\mathrm{D}$, Kumar $\mathrm{S}$ et al. Late-onset intermittent fasting dietary restriction as a potential intervention to retard age-associated brain function impairments in male rats. Age (Dordr). 2012;34:917-33.

16. Streijger F, Plunet WT, Plemel JR et al. Intermittent fasting in mice does not improve hindlimb motor performance after spinal cord injury. J Neurotrauma. 2011;286:1051-61.

17. Tajes M, Gutierrez-Cuesta J, Folch J et al. Neuroprotective role of intermittent fasting in senescence-accelerated mice P8 (SAMP8). Exp Gerontol. 2010;45:702-10.

18. BaHammam A, Alrajeh M, Albabtain $M$ et al. Circadian pattern of sleep, energy expenditure, and body temperature of young healthy men during the intermittent fasting of Ramadan. Appetite. 2010;54:426-9.

19. Froy O, Chapnik N, Miskin R. Effect of intermittent fasting on circadian rhythms in mice depends on feeding time. Mech Ageing Dev. 2009;130:154-60.

20. Carlson AJ, Hoelzel F. Apparent prolongation of the life span of rats by intermittent fasting. The Journal of nutrition. 1946;31:363-75.

21. Karbowska J, Kochan Z. Intermittent fasting up-regulates Fsp27/Cidec gene expression in white adipose tissue. Nutrition. 2012;28:294-9. 
22. Harvie MN, Pegington M, Mattson MP et al. The effects of intermittent or continuous energy restriction on weight loss and metabolic disease risk markers: a randomized trial in young overweight women. Int J Obes . 2011;35;714-27.

23. Hassanein MM. Diabetes and Ramadan: how to achieve a safer fast for Muslims with diabetes. Br J Diabetes Vasc Dis. 2010;10:246-50.

24. Faris MA, Kacimi S, Al-Kurd RA et al. Intermittent fasting during Ramadan attenuates proinflammatory cytokines and immune cells in healthy subjects. Nutr Res. 2012;32:947-55.

25. Shehab A, Abdulle A, El Issa A et al. Favorable changes in lipid profile: the effects of fasting after Ramadan. PloS one. 2012;7:e47615. Epub 2012/11/01.

26. Zare A, Hajhashemi M, Hassan ZM et al. Effect of Ramadan fasting on serum heat shock protein 70 and serum lipid profile. Singapore Med J. 2011;52:491-5.

27. Khan NB, Khan MH, Shaikh MZ et al. Effects of Ramadan fasting on glucose levels and serum lipid profile among type 2 diabetic patients. Saudi Medl J. 2010;31:1269-70.

28. Nomani MZ, Hallak MH, Nomani S et al. Changes in blood urea and glucose and their association with energy-containing nutrients in men on hypocaloric diets during Ramadan fasting. Am J Clin Nutrit. 1989;49:1141-5.

29. Dewanti L, Watanabe C, Sulistiawati et al. Unexpected changes in blood pressure and hematological parameters among fasting and nonfasting workers during Ramadan in Indonesia. Eur J Clin Nutrit. 2006;60:877-81.

30. Fontana L, Meyer TE, Klein S et al. Long-term calorie restriction is highly effective in reducing the risk for atherosclerosis in humans. Proc Natl Acad Sci. 2004;101:6659-63.

31. Fontana L, Klein S, Holloszy JO et al. Effect of long-term calorie restriction with adequate protein and micronutrients on thyroid hormones. J Clin Endocrinol Metab. 2006;91:3232-5.

32. Meyer TE, Kovacs SJ, Ehsani AA et al. Long-term caloric restriction ameliorates the decline in diastolic function in humans. J Am Coll Cardiol. 2006;47:398-402.

33. Sanz A, Caro P, Ibanez J et al. Dietary restriction at old age lowers mitochondrial oxygen radical production and leak at complex I and oxidative DNA damage in rat brain. J Bioenerg Biomembranes. 2005;37:83-90.

34. Heilbronn LK, de Jonge L, Frisard MI et al. Effect of 6-month calorie restriction on biomarkers of longevity, metabolic adaptation, and oxidative stress in overweight individuals: a randomized controlled trial. JAMA 2006;295:1539-48.

35. Lignot J-H, LeMaho $\mathrm{Y}$. A history of modern research into fasting, starvation and food inanition. In McCue MD (ed). Compariative Physiology of fasting, starvation and food limitation. Springer-Verlag, Berlin 2012,17-23.

36. McDonald SD. Management and prevention of obesity in adults and children. CMAJ : Can Medl Assoc J 2007;176:1109-10.

37. Lang A, Froelicher ES. Management of overweight and obesity in adults: behavioral intervention for long-term weight loss and maintenance. Eur J Cardiovasc Nurs. 2006;5(2):102-14. 35. Day C, Bailey CJ. Obesity in the pathogenesis of type 2 diabetes. $\mathrm{Br} J$ Diabetes Vasc Dis. 2011;11:55-61

38. Tsigos C, Hainer V, Basdevant A et al. Management of obesity in adults: European clinical practice guidelines. Obesity Facts. 2008;1:106-16.

39. Kmietowicz $Z$. Obese patients get inadequate care before and after bariatric surgery, finds review. Br Med J 2012;345:e6890.

Duncan GG, Jenson WK, Fraser RI et al. Correction and control of intractable obesity. Practicable application of intermittent periods of total fasting. JAMA . 1962;181:309-12.

40. Stewart WK, Fleming LW, Robertson PC. Massive obesity treated by intermittent fasting. A metabolic and clinical study. Am J Med. 1966;40:967-86.

41. Birkenhager JC, Haak A, Ackers JG. Changes in body composition during treatment of obesity by intermittent starvation. Metabolism: clinical and experimental. 1968;17:391-9. 
42. Ball MF, Canary JJ, Kyle LH. Tissue changes during intermittent starvation and caloric restriction as treatment for severe obesity. Archives of internal medicine. 1970;125:62-8.

43. Vondra K, Rath R, Bass A, Slabochova Z. Prolonged intermittent fasting in obese women. Effect on activity of energy metabolism enzymes, glycogen concentration, protein and DNA in skeletal muscle (author's transl)]. Protrahovane intermitentni hladoveni u obeznich zen. Vliv na aktivity enzymu energetickeho metabolismu, koncentraci glykogenu, proteinu a DNK v kosternim svalu. Casopis lekaru ceskych. 1976;115:454-7.

44. Klempel MC, Kroeger CM, Bhutani S et al. Intermittent fasting combined with calorie restriction is effective for weight loss and cardio-protection in obese women. Nutrition J. 2012;11:98.

45. Arguin $\mathrm{H}$, Dionne IJ, Senechal $\mathrm{M}$ et al. Short- and long-term effects of continuous versus intermittent restrictive diet approaches on body composition and the metabolic profile in overweight and obese postmenopausal women: a pilot study. Menopause. 2012;19:870-6.

46. Day C, Bailey CJ. The hypocaloric diet in type 2 diabetes - déjà vu. Br J Diabetes Vasc Dis. 2012;12):48-51.

47. Pedersen CR, Hagemann I, Bock T, Buschard K. Intermittent feeding and fasting reduces diabetes incidence in BB rats. Autoimmunity. 1999;30:243-50.

48. Belkacemi L, Selselet-Attou G, Hupkens E et al. Intermittent fasting modulation of the diabetic syndrome in streptozotocin-injected rats. Int J Endocrinol. 2012;2012:962012.

49. Bates HE, Kiraly MA, Yue JT et al. Recurrent intermittent restraint delays fed and fasting hyperglycemia and improves glucose return to baseline levels during glucose tolerance tests in the Zucker diabetic fatty rat--role of food intake and corticosterone. Metabolism: clinical and experimental. 2007;56:1065-75.

50. Lim EL, Hollingsworth KG, Aribisala BS et al. Reversal of type 2 diabetes: normalisation of beta cell function in association with decreased pancreas and liver triacylglycerol. Diabetologia. 2011;54:2506-14.

51. Halberg $\mathrm{N}$, Henriksen $\mathrm{M}$, Soderhamn $\mathrm{N}$ et al. Effect of intermittent fasting and refeeding on insulin action in healthy men. J Appl Physiol. 2005;99:2128-36.

52. Tikoo K, Tripathi DN, Kabra DG et al. Intermittent fasting prevents the progression of type I diabetic nephropathy in rats and changes the expression of Sir2 and p53. FEBS letters.

2007;581:1071-8.

53. Krentz AJ. Type 2 diabetes and atherosclerotic cardiovascular disease: do they share common antecedents? Br J Diabetes Vasc Dis. 2002;2:370-8.

54. Mccallum RW, Fisher M. Review: Comparing cardiovascular outcomes in diabetes studies. $\mathrm{Br}$ J Diabetes Vasc Dis. 2006;6:111-8.

55. Wilding J, Finer N. Weight management and cardiovascular disease: implications of recent and ongoing clinical trials. Br J Diabetes Vasc Dis. 2008;8:170-6.

56. Wing RR, Koeske R, Epstein LH et al. Long-term effects of modest weight loss in type II diabetic patients. Arch Intern Med.1987; 147:1749-53.

57. Henry RR, Wiest-Kent TA, Scheaffer L et al. Metabolic consequences of very-low-calorie diet therapy in obese non-insulin-dependent diabetic and nondiabetic subjects. Diabetes 1986;35:155-

64.

58. Wan R, Camandola S, Mattson MP. Intermittent fasting and dietary supplementation with 2deoxy-D-glucose improve functional and metabolic cardiovascular risk factors in rats. FASEB journal . 2003;17:1133-4.

59. Fontana L, Villareal DT, Weiss EP et al. Calorie restriction or exercise: effects on coronary heart disease risk factors. A randomized, controlled trial. Am J Physiol Endocrinol Metab.

2007;293:E197-202. 
60. Katare RG, Kakinuma $\mathrm{Y}$, Arikawa $\mathrm{M}$ et al. Chronic intermittent fasting improves the survival following large myocardial ischemia by activation of BDNF/VEGF/PI3K signaling pathway. J Molec Cell Cardiol. 2009;46:405-12.

61. Mattson MP, Wan R. Beneficial effects of intermittent fasting and caloric restriction on the cardiovascular and cerebrovascular systems. J Nutrit Biochem. 2005;16:129-37.

62. Wan R, Ahmet I, Brown M et al. Cardioprotective effect of intermittent fasting is associated with an elevation of adiponectin levels in rats. J Nutrit Biochem. 2010;21:413-7.

63. Brown JE. Dysregulated adipokines in the pathogenesis of type 2 diabetes and vascular disease. Br J Diabetes Vasc Dis. 2012;12:249-54.

65. Dunmore SJ, Brown JE. The role of adipokines in beta-cell failure of type 2 diabetes. J Endocrinol. 2013;216:T37-45.

65. Kroeger CM, Klempel MC, Bhutani S et al. Improvement in coronary heart disease risk factors during an intermittent fasting/calorie restriction regimen: Relationship to adipokine modulations. Nutrit Metab. 2012;9:98.

66. Davies AR, Efthimiou E. Curing type 2 diabetes mellitus with bariatric surgery - reality or delusion? Br J Diabetes Vasc Dis. 2012;12:173-6. 